\title{
Manifestaciones artísticas contra la dictadura somocista: la canción protesta y la poesía revolucionaria en Nicaragua
}

\author{
BelÉn AMAdOR Rodríguez \\ Universidad Técnica Luis Vargas Torres de Esmeraldas (Ecuador) \\ orcid.org/0000-0003-4692-202X
}

\author{
Johanna Gabriela Cisneros Palacios \\ Pontificia Universidad Católica del Ecuador sede Esmeraldas (Ecuador) \\ orcid.org/0000-0003-2013-0390
}

Presentación: 13 may. 2018 | Aceptación: 7 sept. 2018 | Publicación: 15 dic. 2018

Cita recomendada: Amador Rodríguez, Belén, y Johanna Gabriela Cisneros Palacios. 2018. «Manifestaciones artísticas contra la dictadura somocista: la canción protesta y la poesía revolucionaria en Nicaragua». Dictatorships \& Democracies. Journal of History and Culture 6: 187-212. doi: https://dx.doi.org/10.7238/dd.voi6.3145.

Resumen: En este trabajo analizamos la importancia de la canción protesta y la poesía revolucionaria como instrumentos de movilización durante la revolución sandinista (1977-1979) en Nicaragua. Durante este período se desarrolló un conflicto armado que acabó con el triunfo del Frente Sandinista de Liberación Nacional (FSLN), movimiento guerrillero que desarrolló una serie de acciones que marcan un punto de inflexión en el campo de la comunicación social. Esta investigación, que parte de la necesidad de buscar nexos entre los acontecimientos políticos, militares y artísticos, se centra en la importancia de estas manifestaciones artísticas en oposición a la dictadura somocista. Para ello hemos realizado un análisis del discurso a través de una muestra significativa de piezas musicales y de poemas, pertenecientes a los cantautores Carlos y Luis Enrique Mejía Godoy y a la escritora Gioconda Belli, tres de los más importantes representantes de ambos géneros.

Palabras clave: canción protesta, poesía revolucionaria, instrumentos de movilización, revolución sandinista, dictadura somocista

Artistic Manifestations against the Somoza Dictatorship: The Protest Song and the Revolutionary Poetry in Nicaragua

Abstract: This paper analyses the importance of the protest song and the revolutionary poetry as instruments of mobilization during the Sandinista Revolution from 1977 to 1979, in Nicaragua. During that period an armed conflict was developed that ended with the triumph of the Sandinista National Liberation Front (FSLN), a guerrilla movement that undertook a number of actions that marked a turning point in the field of 
social communication. This research, which starts from the need to seek links between political, military and artistic events, focuses on the importance of these artistic manifestations in opposition to the Somoza dictatorship. For this purpose we've conducted an analysis of the discourse through a significant sample of musical pieces and poems, which belonged to the singer-songwriters Carlos and Luis Enrique Mejía Godoy and the writer Gioconda Belli, three of the most important representatives of both genres. Keywords: protest song, revolutionary poetry, instruments of mobilization, Sandinista Revolution, Somoza dictatorship

\section{Producción cultural y dictadura somocista}

El ambiente cultural que se vivió en Nicaragua desde principios de los años sesenta pone en evidencia que, simultáneamente al surgimiento del Frente Sandinista de Liberación Nacional (FSLN), se articularon otros movimientos sociales encabezados en su mayoría por estudiantes y artistas. Estos grupos estuvieron integrados mayoritariamente por jóvenes, y se manifestaron en contra de los valores culturales dominantes, de tradición vanguardista. También empezaron a cuestionar la concepción del arte y del intelectual en la sociedad nicaragüense. Parte de esta juventud, que ansiaba un cambio, acabó considerando que su iniciativa cultural encontraba un sentido histórico más allá de la renovación estética en el proyecto político sandinista. No es de extrañar que un elevado número de ellos se convirtieran en importantes cuadros dirigentes o militantes del Frente Sandinista y que sus propuestas pasaran a integrar también el programa histórico del FSLN (Palazón 2008). De hecho, el arte durante la revolución nicaragüense toma una importancia inusitada. La lucha no solo fue armada, ya que no hubo exclusivamente manifestaciones ni acciones de la guerrilla. Antes y después del apogeo de las actividades insurreccionales, se produjeron diferentes formas de manifestaciones artísticas en apoyo a la revolución. Por ello se debe prestar mucha atención a la conexión que existe entre los acontecimientos políticos, militares y artísticos, debido a que se llevaron a cabo acciones en el ámbito cultural que no se habían desarrollado hasta el momento en Nicaragua. Resultan significativas las palabras de Margaret Randall (1992, 23): «Posiblemente es ahora que tenemos la oportunidad de hacer historia por primera vez en la historia». Desde esta perspectiva queda muy clara la intención de los sandinistas: narrar la historia bajo su punto de vista. Se trata de que 
los nicaragüenses construyan su propia historia, al margen de la oficial o en oposición a ella.

La década de los setenta significó para el FSLN, entre otras muchas cosas, el punto de encuentro entre la proyección cultural que Carlos Fonseca consideraba necesaria para llevar a cabo la Revolución y lo que Leonel Delgado $(2002,25)$ ha descrito como «la consolidación de un nuevo paradigma intelectual». En este contexto surgen la poesía revolucionaria y la canción protesta nicaragüense, que son formas de comunicación innovadoras desarrolladas por los sandinistas con las que lograron difundir su mensaje entre la población. Estas dos manifestaciones artísticas forman parte de lo que Beverley $(2011,171)$ denomina superestructura cultural:

Emerge un trabajo que no se caracteriza por ser una representación de la Revolución por parte de los artistas, sino de artistas que se van formando a la par con trabajadores y campesinos, y que logran elaborar un trabajo estético desde y para la revolución.

También un dato importante es que en 1962 Luis Somoza ${ }^{1}$ promulga el Código de Radio y Televisión, bautizado por los periodistas como el "Código Negro”. Esta norma daba amplias facultades a la Guardia Nacional ${ }^{2}$ para censurar a los periodistas y cerrar los distintos medios de comunicación, tanto escritos como audiovisuales. Este Código se hizo para evitar la propaganda en apoyo a la lucha armada, política o ideológica contra el somocismo. Constituía realmente una ley de excepción en contra del ejercicio periodístico y de la difusión de cualquier ideología que no fuera el liberalismo a ultranza o el conservadurismo tradicional (Amador 2008, 161).

El hecho de que los medios impresos estuvieran al margen de este estatuto jurídico no significaba que quedaran fuera de la arbitrariedad so-

1 Luis Somoza Debayle era hijo de Anastasio Somoza García, quien en 1936 derrocó al presidente Roberto Sacasa y se proclamó presidente en 1937 tras unas elecciones llenas de irregularidades. Comenzaba así un largo período en la historia de Nicaragua en el cual la familia Somoza se convertiría en la dinastía que gobernó el país. En septiembre de 1956 Anastasio Somoza fue asesinado y su hijo Luis pasó a ocupar su lugar. Tras la muerte de este le sucedió su hermano Anastasio Somoza Debayle, que gobernó hasta 1979, cuando fue derrocado por el movimiento sandinista.

2 Se trata de un cuerpo creado por el gobierno de los Estados Unidos en 1934. Está al servicio de los Estados Unidos. 
mocista. El 22 de enero de 1967 el Partido Conservador organizó una gran manifestación ante el Palacio Nacional de Managua, que acabó en tragedia. Seis días después una parte de la burguesía se reveló. Fue entonces cuando el somocismo promulgó un decreto que concedía al poder ejecutivo la posesión de la maquinaria con la que se editaban los periódicos. De esta manera el propio dictador decidía si se violaba la libertad de expresión. Este decreto estaba dirigido contra el diario La Prensa, ${ }^{3}$ pero su formulación también estaba encaminada a impedir la circulación de los periódicos obreros de la época. Con esta medida se evitaba la difusión de cualquier ideología diferente a la establecida: el bipartidismo fue la norma política imperante en Nicaragua desde la independencia (1821) hasta el 19 de julio de 1979, año en el que sería derrocada la dictadura. Durante sus últimos años, la Jefatura de Radio y TV impuso más de cien cierres y cuantiosas multas (Amador 2008, 161). Debido a la censura existente, el FSLN utilizó la poesía y la música tanto para transmitir sus mensajes políticos y sociales como para movilizar a la población física e ideológicamente.

Estas manifestaciones artísticas no surgen al cien por cien de manera esporádica, ya que en Nicaragua los sandinistas adoptan la misma estrategia de comunicación que los rebeldes de Sierra Maestra, que se apoyaban en la creación de símbolos revolucionarios como la barba, el fusil, el brazalete o el uniforme verde olivo; en golpes de efecto que entusiasmaban a la prensa y captaban la atención del lector; en la reivindicación de la herencia independentista de José Martí y un estricto control de las palabras en discursos y entrevistas. En el caso del país centroamericano el héroe nacional es Sandino en vez de Martí. De la experiencia cubana surgió un proceso de mímesis que, en algunos casos, llegó casi a la simetría. Podríamos afirmar que la Revolución cubana —además de incitar la movilización de la juventud radicalizada del subcontinente- produjo un fuerte impacto en el mundo mítico y simbólico de la izquierda radical, ya que «no fue la realidad en la que se desarrollaba la vida de cientos de estudiantes radicalizados lo que les empujó a crear efímeros grupos

3 Pedro Joaquín Chamorro fue director de este diario desde 1948. Este medio de comunicación se convierte en un firme opositor de la dictadura somocista al final de la década de los setenta, e inaugura una etapa de un periodismo diferente al que existía, con notas impactantes sobre la corrupción y el carácter criminal del régimen gubernamental.

DICTATORSHIPS \& DEMOCRACIES 6 (2018) · E-ISSN: 2564-8829 · PUNCTUM, UNIVERSITAT OBERTA DE CATALUNYA \& FUNDACIÓ CARLES PI I SUNYER 
guerrilleros, sino el mito creado en torno a la victoria revolucionaria por la vía de la lucha armada» (González 1984, 66). No obstante, existen voces como la del historiador de arte nicaragüense y periodista de El Nuevo Diario, Porfirio García Romano (2009), que insisten en el significado del arte como parte de «un proceso popular y social de Nicaragua». En esas formas de expresión no existían razones estéticas, sino que servían y tenían «un carácter utilitario y funcional para la sociedad» (LaRoque 2009).

Este contexto de guerra en Centroamérica es tal vez el más crucial de su historia musical, tanto si observamos el conjunto de su producción y consumo como si atendemos a los estudios realizados sobre ella. En Nicaragua, al igual que ocurrió en Cuba en 1969, donde nació la nueva Trova Cubana, aparece un grupo de artistas ligados al proceso revolucionario. Los más representativos por la repercusión que tuvieron fueron los hermanos Mejía Godoy, ${ }^{4}$ que contaron con el apoyo de Los de Palacagüina, Mancotal y Pancasán. El folklore de Rivas, de Cosigüina y del pueblo anónimo inspira sus ritmos y sus letras. Nos encontramos ante una amplia lista de músicos y cantantes que pretendían no solo cantar sino hacer la historia. De hecho, Carlos Mejía Godoy afirma:

Mis primeras canciones, nacidas en mi exilio voluntario en Costa Rica, son un reflejo del momento histórico de mi país, de Centroamérica y América Latina en general. Son canciones que denuncian la injusticia en Nicaragua bajo la dictadura militar de Somoza Debayle, la tierra en pocas manos, la explotación de los obreros, el crimen y la tortura. En fin, no se diferencian mucho de las canciones de Viglietti, Zitarrosa, Víctor Jara o Violeta Parra, por mencionar algunos (citado en Martins \& Saldías 2002).

En lo que se refiere a poesía, la lista de poetas entrelazados con los fundamentos de Sandino en Nicaragua es muy extensa. De hecho, el Frente Sandinista de Liberación Nacional fue fundado en 1961 por el joven estudiante universitario Carlos Fonseca Amador, que era poeta e hizo varios

4 Carlos y Luis Enrique Mejía Godoy son dos de los más importantes representantes de la Nueva Canción de Nicaragua. Comprometidos con la causa revolucionaria participaron activamente en el período de gobierno de la Revolución Sandinista (1979-1990). Su obra, de contenido altamente social, es muy importante en la historia de la música de Nicaragua y de toda la desarrollada en español. 
trabajos académicos sobre Rubén Darío, además de fundamentar a nivel teórico el nuevo movimiento del Frente Sandinista en esos años. En 1954, junto con otros compañeros, fundó la revista Segovia y dirigió los primeros cuatro números de los seis que lograron salir. Allí publicó artículos y poemas, como los «16 versos del Molendero». Sus lecturas incluyeron a muchos poetas latinoamericanos y nicaragüenses. Murió en combate contra la Guardia Nacional en la región de Zinica el 7 de noviembre de 1976 (Campos 2009).

\section{La importancia de las organizaciones populares}

Teniendo en cuenta la situación de Nicaragua, resultó vital para las manifestaciones artísticas la relación entre el movimiento guerrillero y su red asociativa, formada por las distintas organizaciones de masas que apoyaron la lucha guerrillera. En Nicaragua, tanto unas como otras se caracterizaron por la dependencia de las organizaciones a favor de los intereses del FSLN y por su subordinación a la estrategia de la lucha armada. En este sentido, la articulación entre guerrilla y movimiento popular tuvo un proceso inverso al de la mayoría de los países de América Latina, especialmente El Salvador y Guatemala, donde primero se activó el movimiento popular y después este se vinculó a las organizaciones guerrilleras (Martí i Puig \& Close 2013).

A este respecto, resultaron fundamentales las Comunidades Eclesiales de Base (CEBs). Se trataba de pequeños grupos cristianos implantados a escala local, con un número no superior a cien miembros en cada uno de ellos, cuya principal función consistía en fomentar la participación, la igualdad y la ausencia de liderazgo clerical, así como el análisis bíblico y una toma de conciencia social y política. Fueron una creación de la jerarquía católica, concretamente de Monseñor Rossi, quien en 1956 las impulsó en su diócesis brasileña para paliar la ausencia de sacerdotes, si bien en poco tiempo se radicalizaron para adoptar el pensamiento liberador, emanado de la teología de la liberación. ${ }^{5}$ Las CEBs surgieron en Nicara-

5 Se trata de la prelatura de Barra do Pirai, en el nordeste de Brasil. Este nordeste brasileño presentaba en torno a los años sesenta los siguientes indicadores: 1,5 millones de kilómetros cuadrados DICTATORSHIPS \& DEMOCRACIES 6 (2018) · EISSN: 2564-8829 • PUNCTUM, UNIVERSITAT OBERTA DE CATALUNYA \& FUNDACIÓ CARLES PI I SUNYER 
gua en 1966 por el impulso del sacerdote español José de la Jara, al frente de la parroquia de San Pablo de Managua (Dueñas 2013, 32).

La labor más importante de estas organizaciones no fue solo la toma de conciencia ante la injusticia y la opresión, sino su movilización efectiva contra estas situaciones. Desde la iglesia se llegó a una considerable sensibilización debido a que, además de dedicarse a los estudios bíblicos, las comunidades cristianas que hemos mencionado organizaban talleres de poesía sobre la realidad social. De hecho, durante la década de los ochenta alcanzó gran popularidad la poesía de Solentiname, comunidad campesina a la que se trasladó el sacerdote y poeta Ernesto Cardenal. En palabras de Mayra Jiménez (1979): «Asistían a las sesiones desde niños de entre cinco y doce años hasta personas como doña Olivia, madre de seis sandinistas guerrilleros, poetas y pintores». Se trataba de una poesía comprensible para cualquier persona, al margen de su edad o nivel cultural, y que rompía con la concepción elitista del arte. En este sentido, MacLuhan es taxativo:

Es erróneo suponer que existe una diferencia básica entre la educación y la diversión. Esta distinción no hace más que liberar a la gente de su responsabilidad de entrar al fondo del asunto. Es lo mismo que establecer una distinción entre la poesía didáctica y la poesía lírica basándose en que la una enseña y la otra divierte. Y, sin embargo, nunca ha dejado de ser cierto que lo que agrada, enseña de modo mucho más efectivo (citado en Torrego 1999, 80).

A las condiciones objetivas para el levantamiento revolucionario (la pobreza mayoritaria), se les sumaron las condiciones subjetivas (la toma de conciencia a partir de las CEBs y de su labor politizadora), lo cual debió llevar a la irreversibilidad del conflicto (Dueñas 2013, 48). El trabajo de organización de los cristianos lo realizan dirigentes que ya son miembros del Frente Sandinista. Pero al mismo tiempo, muchos militantes cristianos desaparecen y pasan a la clandestinidad y a la lucha armada. Así, la

a lo largo de 9 estados, 23 millones de habitantes y renta per cápita en torno a los 10o\$, 70\% de analfabetismo y 50\% de mortalidad infantil (Smith 1991, 145). Es una zona de una gran pobreza debido a grandes sequías frente a una zona industrial y algunas grandes ciudades (De Broucker \& Cámara 2009, 37-38).

DICTATORSHIPS \& DEMOCRACIES 6 (2018) · EISSN: 2564-8829 · PUNCTUM, UNIVERSITAT OBERTA DE CATALUNYA \& FUNDACIÓ CARLES PI I SUNYER 
unidad se realiza no solo en el nivel ideal, sino también en el de militancia organizada. Los cristianos son reconocidos no únicamente como auténticos revolucionarios, sino como miembros plenos de la vanguardia. Nace este nuevo tipo de militante y de nicaragüense que es el sandinista cristiano (Girardi 1987, 250). La colaboración de los cristianos con los sandinistas se desarrolla en tres niveles:

Por un lado, hay grupos, parroquias, colegios, etcétera, que le dan al Frente un apoyo externo, concienciando al pueblo y movilizándose para determinados objetivos, señalados por el mismo Frente. Por otro lado, amplios sectores, coordinados en el "movimiento cristiano" se vinculan orgánicamente con la organización guerrillera, y, por último, los creyentes organizados como tales constituyen así una de las organizaciones intermedias del FSLN con los sindicatos, los estudiantes, los trabajadores del arte que hacen estricta y eficaz la vinculación entre la vanguardia y las masas (Girardi 1987, 250).

Por su parte, Humberto Ortega ${ }^{6}$ (1981) afirma en su libro Cincuenta años de lucha Sandinista que la sociedad nicaragüense había sufrido una rápida radicalización y que el FSLN tenía que capitalizarla. También Orlando Núñez manifestó que:

En América Latina no se puede esperar que las condiciones objetivas originen las contradicciones, y que, a su vez, engendren la conciencia marxista a partir de la cual queremos que se guíe nuestra lucha revolucionaria... No es posible posponer la toma del poder en beneficio del proletariado hasta el día ilusorio en que acuda a nosotros un ejército de trabajadores luciendo el uniforme proletario (citado en Ortega 1981, 1-2).

Estas declaraciones se sitúan en la misma línea que las siguientes de Pablo Barreto (1980, 82):

6 Junto a sus hermanos, Camilo y Daniel, Humberto Ortega fue un relevante miembro del Frente Sandinista de Liberación Nacional (FSLN) que participó activamente en la lucha contra la dictadura de la familia Somoza y fue uno de los principales ideólogos de la insurrección urbana y de la tendencia Tercerista. 
Las masas, encabezadas por los trabajadores y los campesinos, buscan cómo estructurar una sociedad más justa, una sociedad en la que no haya explotadores ni criminales, ni ladrones, ni saqueadores, ni asaltantes como la pandilla somocista, que siempre fue apoyada por el Gobierno Imperialista de los Estados Unidos.

Se trataba, pues, de una coyuntura en la cual la sociedad nicaragüense se politizaba rápida e intensamente. Tal radicalización fue encauzada por el FSLN, una organización que, ante todo, era un actor político que quería transformar una realidad que consideraba injusta y altamente represiva. No es gratuita, en este sentido, la expresión acuñada en Nicaragua antes del triunfo de la insurrección que dice: «En Nicaragua ser joven era un delito» (Martí i Puig \& Close 2013, 117). También el cura guerrillero y posteriormente ministro de Cultura, Ernesto Cardenal (1998, 50), plasmó esta idea en uno de sus poemas:

Eran de 20, de 22, de 18, de 17, de 15 años.

Los jóvenes matados por ser jóvenes. Porque tener entre 15 y 25 años en Nicaragua era ilegal.

Y pareció que Nicaragua iba a quedar sin jóvenes.

(«Muchachos de La Prensa», vv. 40-43)

Tampoco se debe obviar el papel que jugó el movimiento estudiantil, que a través del Frente Ventana o el Frente Estudiantil Revolucionario (FER) - este último apoyado por los sandinistas-, diseñó todo un imaginario alrededor de la lucha revolucionaria que incluía el poder simbólico de los mártires de la causa, con los que las nuevas generaciones podían identificarse cultural y generacionalmente. A diferencia de lo ocurrido durante la década anterior, los nuevos proyectos intelectuales quedaron ligados al FSLN ya no de forma solidaria, sino desde el compromiso de la militancia. Esto marca una diferencia fundamental entre ambos proyectos, pues supone el momento en el que el FSLN decide liderar de forma sistemática y estratégica las iniciativas culturales en un contexto propicio para encararlas desde una perspectiva revolucionaria y adscribirlas a su lucha política (Palazón 2008). 


\section{Instrumentos de movilización}

Si la música que asociamos a la guerra de Vietnam es la de Jimmy Hendrix, The Doors o Jefferson Airplane, la guerra de Irak encontró en el rap la mejor manera de expresarse en Estados Unidos. Los soldados que aparecen en Gunner Palace se quejan de la indiferencia con que se siguen sus peripecias desde Estados Unidos y cantan rap ante las cámaras. Este "rap de guerra" expresa la difícil situación en la que muchos de estos soldados viven, con largos períodos de servicio y escasos días de permiso en el cercano Qatar, sin poder viajar a Estados Unidos. Si el heavy metal podía ser considerado hasta entonces la música preferida de la tropa, y el rap y el hip hop lo desbancaron durante la ocupación de Irak (Pizarroso 2005, 435), la revolución sandinista también tuvo su música: el son nica. La popularidad de los hermanos Mejía Godoy sobrepasó la frontera del país centroamericano y su música fue conocida en Europa. Prueba de ello es que canciones como «El zenzontle pregunta por Arlen», que llegaron a cantarse en las manifestaciones durante la insurrección, fueron también tarareadas en España.

Más allá de ese aspecto, lo más significativo es la intención del mensaje que estas manifestaciones artísticas emiten, que es la oposición a la dictadura somocista. Teniendo en cuenta que la mayoría de nicaragüenses no sabían leer ni escribir, estas formas de comunicación consiguen muy buenos resultados. Su efectividad radica en que, al igual que la radio, es un medio oral. Ernesto Che Guevara (1972), refiriéndose a la música y a la radio, afirmó que «enseña, enardece, determina en amigos y enemigos sus posiciones futuras» (citado en Vázquez 2004, 110).

En lo que se refiere a la perspectiva de nuestra investigación, la abordaremos desde la Historia social de la comunicación, que tiene como tema de estudio ineludible el análisis del discurso propagado y el interés por la intencionalidad del emisor al transmitir un determinado mensaje. Edward Thompson $(1981,50)$ nos da pistas de cómo hacerlo:

En realidad cuando [los historiadores] examinan los jeroglíficos mayas más antiguos o las inscripciones cuneiformes de la antigua Babilonia, las intenciones de quienes los grabaron constituyen, precisamente, un importante objeto 
de estudio: y, a través de ellas, la recuperación de su cosmología, su astrología y sus calendarios, sus exorcismos y encantamientos, en suma, los "intereses" de los autores de aquellos mensajes. Los datos empíricos intencionales (los datos intencionadamente proporcionados a la posteridad) pueden ser estudiados, en el marco de la disciplina histórica, con tanta objetividad como los datos no intencionales (esto es, la mayor parte de los datos históricos, que sobreviven por razones independientes de los propósitos de los actores). En el primer caso, las intenciones son ellas mismas un objeto de investigación; y en ambos casos los "hechos" históricos son "producidos", por medio de disciplinas apropiadas, a partir de los hechos empíricos.

Como hemos dicho anteriormente, el uso de la canción protesta y de la poesía revolucionaria se encuentra directamente relacionado con el conflicto violento. De ahí que tenga gran importancia justo en el momento en que estalla el enfrentamiento armado. Estas manifestaciones servían para motivar e inspirar a la audiencia a la que se dirigían, para contribuir a que lo aparentemente imposible pareciera posible. Se trata de narraciones de protagonistas que buscan convencer de lo verdadero y fiable del testimonio que expone y de la importancia de los hechos y lo que estos representan, al tratarse de un otro ejemplar (Rueda Estrada \& Vázquez Medeles 2015, 468). Mediante la narración testimonial se logra hacer del relato militar un relato popular (Gatica 2014, 8).

Esta investigación se ha centrado en dos trabajos: en el poemario Línea de Fuego de Gioconda Belli, que fue publicado en La Habana por Ediciones Casa de las Américas en 1978, un año antes de que el Frente Sandinista de Liberación Nacional llegase al poder; y en el álbum Guitarra Armada, que Carlos y Luis Mejía Godoy publican en 1979. ${ }^{7}$ Ambos trabajos se han seleccionado con el objetivo de analizar cómo las manifestaciones artísticas, en este caso la poesía y la música popular, pueden jugar un papel directo en el apoyo de un movimiento revolucionario.

En el caso de Línea de Fuego, la autora realizó esta obra en Costa Rica, donde se encontraba por oponerse al régimen del general Anastasio Somoza Debayle. Fue condenada a prisión, se exilió primero en México y 
después en este país centroamericano. Desde 1970, año en que comenzó a escribir sus poemas, como muchos intelectuales de su generación se integró en la organización guerrillera. En aquel momento se trataba de un movimiento clandestino y perseguido, cuyo objetivo era el derrocamiento del régimen somocista. De ahí que su compromiso político esté muy presente en su obra, sobre todo en los tres primeros poemarios: en el que hemos nombrado anteriormente y también en Sobre la grama (1970) y en Truenos y arco iris (1982). Hemos decidido centrarnos en Línea de Fuego porque a partir de esta obra se crean los Centros Populares de Cultura en las distintas regiones del país, donde se realizan talleres de poesía.

En cuanto a Guitarra Armada, nos ha llamado la atención porque con estos temas los sandinistas pretendían resolver el problema de cómo enseñar a la población el modo de cuidar y usar las armas que expropiaban a la Guardia Nacional somocista. Si analizamos algunos fragmentos de estas canciones, que se pasaban por Radio Sandino, comprobamos cómo enseñan, por ejemplo, a armar o desarmar un Fusil Automático Ligero (FAL) o a elaborar explosivos caseros. En la misma línea se sitúan los dos anteriores LPs de este dúo: El son nuestro de cada día (1977) y La nueva milpa (1978).

No debemos olvidar que las canciones son un producto resultante del cruce entre la cultura oral y la cultura escrita. Es una de las múltiples manifestaciones en las que se ve que la oralidad y la cultura escrita siguen estando entrelazadas en nuestra sociedad. Entre ellas la instrucción era casi totalmente oral: «Antes de que apareciera la imprenta, los jóvenes aprendían escuchando, mirando, actuando» (Torrego 1999, 80). En esta misma línea se manifiesta Gabriel Celaya, uno de los poetas españoles más representativos de la poesía social de los cincuenta y quien afirma que en su juventud presentía un nuevo género literario, pues pensaba que la poesía cantada estaba llamada a renacer. Concretamente hablaba «de un renacer de la poesía popular que pudiese extenderse y llegar a un gran número de personas» (citado en Torrego 1999, 81). Así, a partir de este género, con el que colaboraban poetas, el FSLN pudo llegar con facilidad a muchísimos más nicaragüenses.

Este nuevo formato a la hora de transmitir el mensaje tiene especial relevancia durante los años sesenta y setenta no solo en América Latina. 
Puede decirse que es un agente de educación informal que se caracteriza por la intención de enfatizar la relevancia de toma de conciencia de la realidad, que permite un rechazo crítico de las estructuras manipuladoras en las que el pueblo ha vivido o vive inmerso (Torrego 1999, 64).

Algunos estudios sobre técnicas de persuasión, como los de James A. Brown (1986), apuntan que la voz humana refuerza considerablemente la argumentación. De hecho, podríamos referirnos a la radio, hasta nuestros días, como el medio más universal de propaganda: un canal con la capacidad de llevar a cualquier lugar del mundo la palabra hablada, que es el método más antiguo - $-\mathrm{y}$ de los más efectivos- de persuasión. El costo de poner en marcha una emisora rudimentaria, así como el de los aparatos de recepción, es relativamente barato; por otra parte, la radio puede llegar en principio a cualquier público, pues no es necesario saber leer para acceder a sus contenidos (Vázquez 2004, 110).

Las radioemisoras, principalmente de onda corta, se han utilizado durante la guerra, y se usan todavía, con fines de propaganda interior y exterior. Los dirigentes sandinistas daban gran importancia a este medio de comunicación. Y es que también en esta guerra la radio es, desde su nacimiento, el principal instrumento de propaganda de guerra para los sandinistas, quienes eran conscientes de «su eficacia en cualquier conflicto» (Pizarroso 2005, 375). El caso de Radio Sandino es un claro ejemplo de que sin esta emisora hubiese sido difícil mantener la huelga que se realizó entre el nueve y el veinte de septiembre: «Sin una radio para orientar al movimiento de masas no habría habido triunfo revolucionario» (comandante Humberto Ortega citado en Mattelart 1986, 35).

\section{Obligación patriótica y emotividad en las canciones de los Mejía Godoy}

Las canciones que se han analizado pertenecen, como hemos dicho anteriormente, a Guitarra Armada (1979). Hemos seleccionado estrofas de tres temas: «Qué es el FAL», «Los Explosivos» $\mathrm{y}$ «El zenzontle pregunta por Arlen». Estas composiciones son bastante significativas del estilo del disco.

Por un lado, las dos primeras canciones instan directamente al pueblo nicaragüense a coger las armas para "sumarse a la causa", con lo cual refle- 
jan el carácter bélico de esta obra musical, que está muy presente en casi todas sus canciones. «El zenzontle pregunta por Arlen» es un homenaje, cargado de emotividad, a una joven que luchaba a favor de la revolución: Arlen, al igual que otros nicaragüenses, es una mártir. El martirio es un fenómeno complejo. Si bien permanece ajeno a nuestras ideas políticas modernas, el estudio del martirio como evento cohesionador y movilizador social permite observar un conjunto de acciones socialmente significativas (López Menéndez, 2009). La movilización social que los mártires suelen provocar se construye en torno a la imposibilidad de separar nítidamente las esferas política y religiosa. Los dos reinos están entrelazados y, además, se comunican, por lo que diferenciarlos implica erosionar la propia lógica del martirio (López Menéndez, 2015).

El título de la canción «Qué es el FAL» es bastante explícito de la función con la que fue concebido: explicar qué es el Fusil Automático Ligero (FAL). Podemos observar términos y expresiones coloquiales, fáciles de entender, como «logramos de zopetón» 0 «lo consigo por quintales». La comprensión del mensaje no requiere ningún esfuerzo. Se trata de una instrucción al receptor, a quien se le dan unas nociones básicas sobre cómo utilizar esta arma y se le da a entender que no exige dificultad alguna. Debemos tener en cuenta que gran parte de la población nicaragüense del momento no sabía leer ni escribir, algo que tuvieron muy en cuenta los sandinistas a la hora de comunicar sus ideas e intentar ganar adeptos.

Quebramos el arma ahora,

llegó la hora de separar

la laminita del cierre.

La masa viene saliendo ya.

Le tiramos la cubierta

y así logramos de zopetón

poner a un lado este asunto

y aparte el conjunto del cañón.

Cuando el tapón de los gases

fuera de base lo pongo yo,

la varilla y su consorte,

que es el resorte, sacando voy. 
Separo el pistón de gases

de su resorte matrimonial

y así queda en puras piezas

esta belleza llamada FAL.

(vv. 25-40)

La canción «Los explosivos» es del mismo estilo que la anterior. Explica cómo fabricar bombas caseras, al mismo tiempo que anima a los receptores a participar en la lucha. Hace referencia a la «ofensiva final» (v. 23), es decir, al ataque decisivo por parte de los sandinistas que dio la victoria y acabó con la dictadura somocista. Para ese momento, requieren al pueblo que prepare explosivos, los cuales - como la letra de esta canción indica- pueden prepararse de manera artesanal:

Cuando se acerque el momento

de la ofensiva final

a la calle todo el pueblo

a poner su grano de maíz.

Queremos ver en tu casa

para las bombas construir

carbón vegetal y grasa,

azúcar y aserrín.

Si el tal nitrato de amonio

te cuesta mucho encontrar,

en las fábricas de abono

lo podés recuperar.

$\mathrm{Si}$ es el aluminio negro

lo consigo por quintales

en las fábricas y centros

de pinturas comerciales.

(vv. 22-37)

Al contrario que las dos canciones que acabamos de analizar, el estilo de «El zenzontle pregunta por Arlen» es totalmente diferente. Aquí el eje central es la emotividad, ya que se apela directamente a los sentimientos. Se 
narra la muerte de Arlen Siú, una poetisa joven conocida popularmente como «la chinita de Jinotepe», que vivía en un pueblo cercano a Managua y que fue asesinada por la Guardia Nacional del dictador Somoza en 1975. Cuatro años después, en las manifestaciones de 1979, los nicaragüenses recordaban a la joven a través de esta canción:

Le encuentro zenzontle amigo

que donde la chinita peleó hasta el final

nació un manantial quedito

que a cada ratito le viene a cantar.

Enterró en el hueco de su guitarra

el lucero limpio de su corazón,

se fue río arriba pa' la sabana

como un lirio de agua serenito.

(vv. 23-31)

El retrato de Arlen estuvo presente en las manifestaciones de protesta que siguieron a su muerte, erigido en símbolo de la brutalidad del gobierno. En este caso el martirio es constituido por un dispositivo cultural que resalta la supervivencia de un grupo marginado como mecanismo de resistencia y de creación de identidades que asume forma política y cuestiona la dictadura (López Menéndez 2015). Al considerarla mártir, los sandinistas no solo reconocen su muerte ejemplar, sino que la convierten en una figura representativa de sus valores y aspiraciones. Mediante este personaje se critica un determinado aspecto de la realidad. Frente a estos personajes el cantautor no es neutral; antes al contrario, se identifica con ellos o los rechaza, gozan de su afecto o de su desdén (Torrego 1999, 106). Una idea que se resume perfectamente en esta estrofa:

Mire, compañero, la verdad es que no se puede hacer la revolución sin la participación de las mujeres; en el ejército de Sandino, María de Altamirano, Conchita Alday y Blanca Arauz, y en nuestra Organización, en el Frente Sandinista: Luisa Amanda, María Castil, Claudia, Arlen, Mildred. 
Compadre Guardabarranco, hermano de viento, de casta y de luz, decime si en tus andanzas viste una chavala llamada Arlen Siú. (vv. 1-7)

Los hermanos Mejía Godoy, como cantautores que son, quieren llegar de una manera clara y sin distorsiones al oyente. De ahí que su lenguaje intente ser comprensible para gran parte del público. Aun así, no renuncian, pese a su empeño por subrayar una comunicación real y efectiva, a la ambivalencia, a lo implícito, al doble sentido, a la ambigüedad, obligando al destinatario de la canción a aprender toda una clave de símbolos e imágenes, a mantener una escucha activa, condición necesaria para el aprendizaje (Torrego 1999, 64). Un ejemplo es «El zenzontle pregunta por Arlen». A través de este pájaro, que tiene un canto característico, se establece un paralelismo entre la existencia humana y la presencia natural del paisaje de la patria (Martins \& Saldías 2002).

La canción sugiere que, para buena parte de Nicaragua, resultó natural rebelarse contra las circunstancias del momento. Quienes actúan en nombre de las clases populares están fusionados con el conjunto de la nación; y si la violentísima Guardia Nacional desapareciera, Nicaragua se libraría de una carga y ninguna parte del país la extrañaría, ningún pájaro cantaría pidiendo su regreso. Haciendo referencia al mundo natural se invoca no solo a aquella militante, sino a todos los que han caído en combate luchando contra la dictadura, y se relaciona directamente su presencia con la pureza del entorno que existirá cuando «la patria sea reconstituida, como debe ser, cuando la naturaleza sea restaurada» (Scruggs 2006, 9). El estilo musical es el denominado son nica, cuyos principales instrumentos son «la marimba de arco propia de Nicaragua y las terceras armonizadas en la guitarra, originalmente típicas de la música vocal de la región» (Scruggs 1998, 749). El objetivo de esta canción es generar sentimiento de unanimidad. Como afirma Domenach (1993, 74-75), «el canto colectivo es el medio más seguro de fundir una muchedumbre en un solo bloque, y de inspirarle el sentimiento de que constituye un solo ser». Y es que, entre todas las formas de expresión artística, «la música es probablemente la que tiene un mayor efecto sobre nosotros porque produce emociones fuertes en los seres humanos» (Martiniello 2016, 62). 
A través de estas piezas musicales la organización guerrillera pretendía aumentar la conciencia política de la población; verbalizar los problemas que había que superar; sugerir actuaciones inmediatas para lograrlo; establecer una continuidad histórica con esfuerzos pasados o relacionar las luchas locales con otras mayores; más aun en un sistema que limitaba la cultura del papel a una élite, «pero que no podría impedir que la gente escuchara canciones que trataban de la realidad» (Gilman 2003, 349).

\section{La poesía de Gioconda Belli, una concepción de la revolución desde el amor}

Si analizamos el poemario Línea de Fuego, observamos la concepción del amor como sentimiento y experiencia vinculado a la insurgencia y al compromiso político (Zamora 1991, 951). He aquí dos ejemplos:

Estoy enamorada de vos, perdidamente enamorada

y si te he dejado no es por mucho tiempo, no es para olvidarme de limas y cadenas, no es para olvidar lo que no hay que olvidar.

¡Yo estoy con vos, mi Nicaragua, mi hombre con nombre de mujer!

(«Ah, Nicaragua», vv. 14-20)

Amo a los obreros, esos sudorosos gigantes morenos que salen de madrugada a construir ciudades. Amo a los carpinteros, que conocen a la madera como a su mujer. Y saben hacerla a su modo

[...]

A todos los amo con un amor de mujer, de madre, de hermana.

Con un amor que es más grande que yo toda, que me supera y me envuelve como un océano 
donde todo el misterio se resuelve en espuma.

(«Amo a los hombres y les canto», vv. 7-40)

Gioconda Belli presenta el amor como una metáfora de la unidad sociopolítica y de género en oposición a la tiranía: «Ese amor era arma contra la opresión, el deseo dionisíaco que vence a la muerte, a la desesperación» (Grau Lleveria 1999, 50). Este sentimiento se expone, basándonos en las estrofas que acabamos de citar, como una fuerza que minimiza las divisiones entre las clases sociales y los géneros. Dentro de este contexto podemos decir que Belli representó a la mujer como la entidad destinada principalmente para dar amor, asociada con lo sentimental y con lo pasivo. Ella era la naturaleza y el paisaje nicaragüense, y la tierra que esperaba ser poseída por el amante guerrillero. Estos versos pertenecientes al poema «Yo, la que te quiere» reflejan perfectamente esta idea:

Yo caliento tus noches, encendiendo volcanes en mis manos, mojándote los ojos con el humo de mis cráteres.

Yo he llegado hasta vos vestida de lluvia y de recuerdo, riendo la risa inmutable de los años.

Yo soy el inexplorado camino, la claridad que rompe la tiniebla.

(vv. 5-11)

En estos versos la mujer es concebida como un ser dependiente del sujeto masculino. De ahí que el hombre fuese el protagonista de su poesía, el representante de la fuerza y el dominio en el espacio público. Como afirma Sofía Kearns (2003), «esta dicotomía entre lo femenino y lo masculino correspondía claramente al "viejo orden patriarcal" explicado por Hélène Cixous, donde el primer elemento siempre se subordinaba al segundo». Aun así, lo que más sorprende es que la lucha política de esos tiempos se enroscara con tanta fuerza en sus versos o que la revolución de su pueblo fuera abordada con metáforas tan eróticas (Espejo 2010). 
Por otro lado, encontramos en la poesía de esta nicaragüense una representación femenina muy diferente, que nos indica una nueva concepción de identidad femenina que sitúa a la mujer en el mismo plano que el hombre: como un guerrillero que sale a luchar por su país.

La madre se ha cambiado de ropa.

La falda se ha convertido en pantalón,

los zapatos en botas,

la cartera en mochila.

No canta canciones de cuna,

canta canciones de protesta.

(«La madre», vv. 1-6)

En este caso, nos encontramos con una mujer que ejerce la misma función que un hombre. Se trata de una guerrillera que se dispone a luchar por aquello en lo que cree. De ahí que en el poema «La madre» se incluyan «elementos novedosos de la representación femenina, que pueden interpretarse como fisuras que desestabilizaron el modelo "Mujer", y que son evidencia de la negociación que la escritora hacía entre lo tradicional y lo nuevo respecto a la identidad femenina» (Kearns 2003). Esta es la posición de Gioconda Belli, y también la de la organización a la que pertenece, el FSLN. «Es, por lo tanto normal, absolutamente lógico, que ahora se hable de una nueva revolución: la revolución de la mujer. Es decir, de una revolución que va a completar el proceso de una liberación nacional». Estas palabras fueron publicadas en 1983 por la Revista Envío, palabras que fueron pronunciadas por el comandante Tomás Borge, miembro de la Dirección Nacional del Frente Sandinista de Liberación Nacional, en el discurso de celebración de la AMNLAE. Las mujeres nicaragüenses se organizaron por primera vez de forma masiva durante la lucha contra la dictadura somocista, sobre todo, como una reacción contra la represión que sufrían sus hijos. En 1977 crearon la Asociación de Mujeres ante la Problemática Nacional (AMPRONAC). Con el triunfo de la revolución, cambió de nombre y se llamó AMNLAE (Asociación de Mujeres Nicaragüenses Luisa Amanda Espinoza). Esta joven falleció con 22 años en la ciudad de León y es considerada «la primera mártir del FSLN» (Randall 1980, 43). 
De ahí que no hablemos de muerte, sino de martirio, lo que corresponde «a un proceso de conmemoración llevado a cabo por los creyentes que avalan la narrativa martirial; este implica el establecimiento de límites y la fijación de identidades, así como la creación de mecanismos de legitimidad y liderazgo» (López Menéndez 2015, 18).

También es importante destacar el carácter histórico-testimonial, muy presente en la poesía de Belli. «El testimonio se convierte, entonces, en la tendencia genérica característica de Centroamérica en cuanto a su estrecha vinculación con los movimientos antidictatoriales» (Rueda Estrada \& Vázquez Medeles 2015, 465). En Nicaragua se crearon los Centros Populares de Cultura en las distintas regiones del país, en los que se realizaban talleres de poesía que «se inscribían en una concepción que identificaba la poesía con el trabajo político necesario para provocar modificaciones ideológicas en la población» (Cuevas citado en Palazón 2010, 167). Esta última reflexión lleva a considerar que la poesía de taller fue fundamentalmente testimonial y el lugar para la construcción de una hegemonía cultural ligada al subalterno (Palazón 2010).

Las recopilaciones de testimonios de guerrilleros de base y de quienes participaron en las sucesivas sublevaciones se concentran no solo en los primeros años ochenta, sino incluso antes de la revolución. Charlotte Baltodano recogía en 1977 testimonios para el Centro de Investigación de la Realidad de América Latina (CIRA), y en 1978 Paulo Cannabrava entrevistaba a guerrilleros de varias tendencias, lo que nos permite conocer la relación de fuerzas existente entre ellas. A los trabajos anteriores hay que sumar el de Gabriel García Márquez, Los Sandinistas, que fue publicado en 1979, el año del triunfo de la revolución; y el de Pilar Arias, Nicaragua: Revolución. Relatos de combatientes del Frente Sandinista.

En este sentido, es una poesía que alude constantemente al pasado. Se trataba, tal como expuso Omar Cabezas en su best seller La montaña es algo más que una inmensa estepa verde, de una nueva utopía revolucionaria: «Recuerdo lo que Leonel Rugama dijo al grupo de compañeros que estaba allí discutiendo con él. Frunció el ceño y exclamó: “Hay que ser como el Che... ser como el Che... ser como el Che” (Cabezas 1982, 20). Prueba de ello es el siguiente poema - perteneciente a la obra que estamos analizando, $L i$ nea de Fuego- que explica lo que está ocurriendo y cómo muchos de los 
compañeros de Belli, en este caso su pareja Eduardo Contreras Escobar, conocido como comandante Marcos, ha muerto durante la contienda:

\author{
El ruido de la metralla nos dejó con la puerta en \\ las narices. \\ La puerta de tu vida cerrada de repente \\ en la madera que te duerme y acurruca en el \\ vientre de la tierra. \\ No puedo creer tu muerte, \\ $\tan$ sin despedida, \\ —sólo ese lejano presentimiento de aquella noche, \\ ¿te acordás?- \\ en que lloré rabiosamente viéndote dormido, \\ sabiéndote pájaro migratorio \\ en rápida fuga de la vida. \\ («Comandante Marcos», vv. 1-12)
}

La particularidad de Gioconda Belli es que su poesía es mucho más sentimental. Transmite lo que siente como militante de la organización guerrillera y también como mujer. Desde nuestro punto de vista, aquí radica la singularidad de Línea de fuego, ya que en sus poemas está presente el yo femenino con sus conflictos y contradicciones de identidad. Se identifica con el proyecto patriarcal de la revolución nicaragüense en el que la observamos como una mujer con su ideología y sentimientos particulares.

El estilo de esta poeta es muy diferente al del cura guerrillero Ernesto Cardenal, pero tiene el mismo fin, movilizar y crear conciencia entre la población; así lo confiesa el conocido popularmente como "poeta místico" a Mario Benedetti en una entrevista publicada en La Ventana en el año 2010:

Creo que el poeta debe ser revolucionario, pero creo que todo buen poeta ya hace revolución al revolucionar la lengua, al revolucionar la poesía, aun cuando no tenga una actividad revolucionaria, una actividad política en su vida. Sin embargo, me parece que el poeta debe ser un hombre íntegro, y en ese sentido debe ser también cabal, un hombre íntegro, que se interese por los problemas 
de su pueblo, por la situación económica y por lo tanto que tenga también una actividad revolucionaria en su vida.

Una afirmación que reflejan sus poesías, algunas de ellas escritas en papeles volantes que eran repartidos entre la población.

\section{Conclusiones}

Es innegable la contracultura que se fue generando a lo largo de la guerra de liberación (1977-1979) en Nicaragua. Tras la producción literaria sobre el nacionalismo que llevó a cabo la vanguardia y la dictadura somocista, se produjo una elaboración revolucionaria del nacionalismo que encontró cauce en el sandinismo. A través de este trabajo hemos visto cómo la literatura y la música constituyen una práctica ideológica específica: que la lucha armada se acepte culturalmente como una posibilidad válida.

Tanto Guitarra Armada como Línea de Fuego integran la lucha armada y las narrativas relacionadas con el acontecer nacional. Para ello el testimonio tiene gran importancia y es fundamental para generar un imaginario cultural en torno al pueblo, donde este se ve como el verdadero creador de los cambios sociales y, en consecuencia, como protagonista de la historia y sujeto histórico determinante. Así lo reflejan las canciones y poesías que hemos analizado. Sin embargo, el análisis de la bibliografía y los testimonios tanto de los dirigentes sandinistas como de periodistas que cubrieron estos dos años de lucha insurreccional nos permiten afirmar que se llevaron a cabo una serie de actuaciones en el ámbito de la comunicación que influyeron en la población y los situaron como protagonistas de publicaciones y noticiarios. Pero, más allá de ese aspecto, lo más significativo es la intención del mensaje que emiten estas manifestaciones artísticas, ya que, como ha podido comprobarse en este estudio, la canción protesta y la poesía revolucionaria constituyeron instrumentos de movilización utilizados por los sandinistas. Teniendo en cuenta que la mayoría de los nicaragüenses no sabían leer ni escribir, esta forma de propaganda consigue muy buenos resultados.

Cuando hablamos de propaganda nos referimos «a la expresión de una opinión o una acción por individuos o grupos, deliberadamente orienta- 
da a influir opiniones o acciones de otros individuos o grupos para unos fines predeterminados» (Edwards citado en Pizarroso 1993, 28). De ahí que tanto los hermanos Mejía Godoy como Gioconda Belli apelen a recursos como el amor, la emotividad o el patriotismo para causar un efecto determinado en la población.

Por ello, llegamos a la conclusión de que el protagonismo de los colectivos insurrectos fue la fructificación del trabajo y de la organización desarrollada por los sandinistas durante largos años. El FSLN dio espacios y medios a estos colectivos para expresar sus reivindicaciones, y estos, al salir a la calle, le dieron el poder. También proporcionaron a la organización guerrillera un sustrato social, una base humana, un discurso y un rostro. Ese rostro, mayoritariamente urbano, encarnó la revolución popular sandinista y esta le cedería el discurso. No obstante, y aunque en el Programa Histórico e Ideológico del FSLN y en los discursos de sus dirigentes se habla de una Nicaragua en la que tienen cabida todos los sectores, debemos recordar que tanto una parte del campesinado propietario como de los misquitos de la Costa Atlántica no se integraron, si no excepcionalmente, en el proyecto.

\section{Referencias bibliográficas}

Amador, Belén. 2008. «Nicaragua, periodismo preinsurreccional, 1977-1979», 159179. En Antonio Checa y María del Mar Ramírez Alvarado, eds., Visiones de América. Comunicación, Mujer e Interculturalidad. La Coruña: Netbiblo.

Barreto, Pablo E. 1980. El Repliegue. De Managua a Masaya. México D. F.: Editorial Cártago de México.

Belli, Gioconda. 1978. Línea de Fuego. La Habana: Casa de las Américas. Benedetti, Mario. 2010. «Ernesto Cardenal: Evangelio y Revolución». La Ventana. Portal Informativo de Casa de las Américas. http://laventana.casa.cult.cu/ noticias/2010/01/20/ernesto-cardenal-evangelio-y-revolucion/. Consultado el 3 de febrero de 2018.

Beverley, John. 2011. «Repensando la lucha armada en América Latina». Sociohistórica 28: $163-177$.

Brown, James Alexander. 1986. Técnicas de persuasión. De la propaganda al lavado de cerebro. Buenos Aires: Editorial Universitaria de Buenos Aires.

Cabezas, Omar. 1982. La montaña es algo más que una inmensa estepa verde. Managua: Nueva Nicaragua. 
Campos, Javier. 2009. «Nicaragua tierra de poesía y de revolución». Síbila. Revista de Poesia e Crítica Literária 18 (14 ag.). http://sibila.com.br/cultura/ nicaragua-tierra-de-poesia-y-de-revolucion/3081.

Cardenal, Ernesto. 1998. Vuelos de Victoria. Nueva York: Curbstone Press, 1988.

De Broucker, José, y Dom Helder Cámara. 2009. Selección de textos. Madrid: Movimiento Cultural Cristiano.

Delgado, Leonel. 2002. Márgenes recorridos. Apuntes sobre procesos culturales y literatura nicaragüense del siglo Xx. Managua: Instituto de Historia de Nicaragua.

Domenach, Jean-Marie. 1993. La propaganda política. Buenos Aires: Universidad de Buenos Aires.

Dueñas, Ignacio. 2013. Iglesia y Revolución en Nicaragua a través de los testimonios orales: la experiencia de Solentiname. [S.1.]: Entelequia. Revista Interdisciplinar.

Espejo, Karen. 2010. «La revolución del erotismo». La República 3 (oct.). http:// larepublica.pe/archivo/487444-la-revolucion-del-erotismo.

Gatica, Mariela. 2014. "La discursividad en torno a la lucha armada sandinista a través del testimonio». Revista Estudios 29: 230-246.

Gilman, Claudia. 2003. Entre la pluma y el fusil. Buenos Aires: Siglo XxI Editores Argentina.

Girardi, Giulio. 1987. Sandinismo, marxismo, cristianismo: la confluencia. Managua: Centro Ecuménico Antonio Valdivieso.

González, Mike. 1984. «The Culture of the Heroic Guerrilla: The impact of Cuba in the Sixties». Bulletin of Latin American Research 3 (2): 65-75.

Grau-Lleveria, Elena. 1999. «La poesía erótica de Gioconda Belli: Tradición y alteración», 47-59. Afrodita en el trópico. Erotismo y construcción del sujeto femenino en obras de autoras centroamericanas. Michigan: Scripta Humanística.

Jiménez, Mayra. 1979. «Poesía de Solentiname. Autores Múltiples». Letras 2. http://www. revistas.una.ac.cr/index.php/letras/article/view/1250/1171.

Kearns, Sofía. 2003. «Una ruta hacia la conciencia feminista. La poesía de Gioconda Belli».CiberLetras 9 (2). http://www.lehman.cuny.edu/ciberletras/vog/kearns.html.

LaRoque, Katie. 2009. Graffiti en Managua. Una expresión artística de la juventud nicaragüense. http://digitalcollections.sit.edu/isp_collection/646.

López Menéndez, Marisol. 2009. «The Holy Jester: A story of martyrdom in Revolutionary Mexico». The New School Psychology Bulletin 6 (2): 59-66.

— 2015. «La humanidad de los mártires: Notas para el estudio sociohistórico del martirio». Intersticios Sociales 10: 1-23.

Martí i Puig, Salvador, y David Close. 2013. Nicaragua y el FSLN (1979-2009). ¿Qué queda de la revolución? Barcelona: Edicions Bellaterra.

Martiniello, Marco. 2016. «Música y movilización sociopolítica». Afkar ideas. Revista Trimestral para el Diálogo entre el Magreb, España y Europa 51: 62-64.

Martins, Floriano, y Mónica Saldías. 2002. «Luis Enrique Mejía Godoy. Conversaciones con un trovador errante (entrevista)». Agulha. Revista de Cultura 24. http://www. revista.agulha.nom.br/ag24godoy. 
Mattelart, Armand. 1986. Communicating in Popular Nicaragua. Bristol: SMC Typesseting.

Ortega, Humberto. 1981. Cincuenta años de lucha sandinista. La Habana: Ediciones Especiales.

Palazón, Gema D. 2008. «Polémicas culturales, compromiso intelectual y revolución en Nicaragua». L’Ordinaire des Amériques 211: 9-30. Doi: https://journals.openedition. org/orda/2534.

- 2010. Memoria y escrituras de Nicaragua. Cultura y discurso testimonial en la Revolución Sandinista. Saint Denis: Editions Publibook.

Pizarroso, Alejandro. 1993. Historia de la propaganda, notas para un estudio de la propaganda política y de guerra. Madrid: Ediciones de la Universidad Complutense de Madrid.

- 2005. Nuevas guerras, vieja propaganda (de Vietnam a Irak). Madrid: Ediciones Cátedra.

Randall, Margaret. 1980. Todas estamos despiertas. Testimonios de la mujer nicaragüense hoy. Madrid: Siglo xxI de España Editores.

— . 1992. «¿Qué es y cómo se hace un testimonio?». Revista de Crítica Literaria Latinoamericana 36/18: 21-45.

Rueda Estrada, Verónica, y Juan Carlos Vázquez Medeles. 2015. «Testimonio nicaragüense: de los Sandinistas a la inclusión de los Contras. Por una polémica memoria contrarrevolucionaria». Kamchatka. Revista de Análisis Cultural 6: 463-490.

Scruggs, Tomás M. 1998. «Nicaragua», 747-769. En Dale A. Olsen y Daniel E. Sheehy, eds. The Garland Encyclopedia of World Music: South America, Mexico, Central America and the Caribbean. Londres: Routledge.

—. 2006. «Música y el legado de la violencia a finales del siglo xx en Centroamérica». Trans. Revista Transcultural de Música 10. http://www.redalyc.org/ $\mathrm{html} / 822 / 82201003 /$.

Smith, Christian. 1991. La teología de la liberación. Radicalismo religioso y compromiso social. Barcelona: Editorial Paidós.

Thompson, Edward. 1981. Miseria de la teoría. Barcelona: Crítica.

Torrego, Luis. 1999. Canción de autor y educación popular (1960-1980). Madrid: Ediciones de la Torre.

Vázquez, Miguel. 2004. Guerrilla y Comunicación. La propaganda política del EZLN. Madrid: Los libros de la Catarata.

Zamora, Daisy. 1991. «La mujer nicaragüense en la poesía». Revista Iberoamericana 57/157: 933-958. 